\title{
A proposta pedagógica do M.S.T. para as escolas dos assentamentos (A construção da escola necessária)
}

\author{
Esméria de Lourdes Saveli ${ }^{1}$
}

“... a história das idéias pedagógicas mostra que a pedagogia, isto é, a teoria da educação, é filha das crises sociais e politicas. É essencialmente em período de crise social e política que uma sociedade se interroga sobre a educação que dá à sua juventude..."

(Charlot, 1979:22)

\section{RESUMO}

O texto pretende evidenciar pontos fundamentais da proposta de Educação do M.S.T. para as escolas dos assentamentos. O elemento básico e inovador dessa proposta é o fato de um grupo social organizado se apropriar da escola pública e buscar promover uma educação escolar ligada ao seu projeto social.

Palavras-chave: educação, assentamento, metodologia, currículo

Este é um estudo de natureza conceitual, em que buscou-se evidenciar os pontos fundamentais da proposta pedagógica do Movimento dos Trabalhadores Rurais sem Terra (MST) para as escolas dos assentamentos. $\mathrm{O}$ elemento inovador da proposta pedagógica que emerge do MST refere-se ao sentido da apropriação da escola pública por um movimento social or-

\footnotetext{
${ }^{1}$ Professora da Universidade Estadual de Ponta Grossa - Doutoranda em Educação - UNICAMP - Campinas.

Olhar de professor, Ponta Grossa, 2 (2):61-70, nov. 1999.
} 
ganizado, com o objetivo de promover uma educação escolar intrinsicamente ligada ao seu projeto social.

Trazer algumas informações sobre o Movimento é fundamental para se entender a trajetória histórica da construção do projeto educacional que emergiu no interior do mesmo.

O MST é um movimento de massas de caráter sindical, popular e político. Traz uma bandeira de luta pela terra, a reforma agrária, e propõe mudanças estruturais na sociedade. Surgiu a partir do reaparecimento da luta pela terra no Brasil, nos Estados do Rio Grande do Sul, Santa Catarina, Paraná, São Paulo e Mato Grosso do Sul, através de ocupações que ocorreram nos anos de 1978 e 79. Foi criado como Movimento Nacional em 1984. Em 1995 realizou em Brasília o seu III Congresso Nacional, que aprovou a plataforma de lutas para os próximos cinco anos e o novo lema do MST: Reforma Agrária: uma luta de todos!

A partir desse momento, a tendência do Movimento tem sido a busca de aliados no conjunto da Sociedade. De acordo com dados fornecidos por CALDART(1995), atualmente o MST está organizado em 22 Estados do País, já conquistou mais de mil áreas de assentamento ${ }^{2}$, envolvendo aproximadamente 138 mil famílias.

O Setor de Educação, responsável por tratar da questão do direito à educação e à escola das crianças e dos jovens Sem Terra, foi articulado em nível nacional a partir de 1987. Atualmente o MST acompanha o trabalho de aproximadamente 950 escolas públicas de $1^{\mathrm{a}}$ a $4^{\mathrm{a}}$ séries e 50 escolas de $5^{\mathrm{a}}$ a $8^{\mathrm{a}}$ séries do Ensino Fundamental, em todo o país. Atinge cerca de 40 mil alunos e 1800 professores. Em alguns Estados também se desenvolvem experiências de alfabetização de adultos e de educação infantil. O MST vem, ainda, criando escolas alternativas em nível de Ensino Médio para jovens e adultos dos assentamentos que querem e precisam aprofundar sua qualificação técnica, especialmente nas áreas do Magistério, Produção e Administração.

CALDART(1995) não deixa de registrar que, ao mesmo tempo em que o MST luta pelas escolas que vai ajudando a construir, também precisa lutar com a falta de escolas e com um contingente de aproximadamente 30 mil crianças que ainda não têm acesso à escolarização em muitos assentamentos e acampamentos ${ }^{3}$ do país.

O MST conseguiu elaborar uma proposta de educação porque, em pri-

\footnotetext{
${ }^{2}$ A palavra assentamento refere-se a assentamento rural que é o local, definitivo, de moradia e de produção dos Sem Terra; significa um dos resultados concretos do processo de luta pela terra. (SOUZA, Maria Antonia. Educação em Assentamentos Rurais. Ponta Grossa,1999. Mimeo). ${ }^{3}$ Acampamento é uma das formas/fases de luta do M.S.T., representa o momento em que trabalhadores organizam barracos de lona à beira de estradas ou no interior de propriedade cuja posse está sendo questionada. (SOUZA,1999)
} 
meiro lugar, os seus sujeitos vivem no cotidiano uma diversidade de processos educativos; isto representa uma mudança de postura pessoal, até física, diante das situações, das outras pessoas, diante do poder. CALDART diz que esse processo educativo

transforma camponeses cabisbaixos, culpados, sem auto-estima nem coragem sequer de erguer os olhos diante daqueles que julgam seus superiores, em trabalhadores SEM TERRA, com altivez suficiente para desafiar os poderes constituídos, para olhar direto nos olhos de seus opositores exigiro que julgam ser de direito (1995:8).

Um outro ponto importante é que o MST, diferentemente de outros movimentos sociais, conseguiu sensibilizar outros setores da sociedade para a sua luta, entre os quais, profissionais ligados à Educação.

A questão da escolarização é muito forte no MST desde os seus primeiros acampamentos e assentamentos. A história começa em 1985, no histórico acampamento da Fazenda Annoni, em Sarandi (RS). Naquela ocasião, quando a equipe de educação puxou a discussão sobre a necessidade de se conseguir a implantação de uma escola oficial, no próprio acampamento, para as crianças não perderem o ano escolar, essa discussão foi inusitada até para as lideranças, pois isso significava trazer para dentro de uma situação de con- flito e de mobilidade uma instituição que representa uma dimensão de estabilidade. É CALDART quem explica que, naquele momento

havia mais uma intuição sobre a necessidade de lutar também por este direito de cidadania que é a educação, do que propriamente a clareza da relação que poderia haver entre o acesso à escola e a condução da luta pela terra e pela Reforma Agrária (1995:10).

A escola acabou sendo conquistada em 1986, representando, inclusive, um fato histórico, pois ao colocar uma escola oficial num acampamento, o Estado estava, contraditoriamente, reconhecendo a legitimidade daquela ocupação.

Desde o início da história da relação do MST com a escolarização, houve uma preocupação em discutir a questão sobre por qual tipo de escola se estava lutando. Em todas as reuniões, o centro de discussão girava em torno do mote: uma escola diferente. Com essa adjetivação, acampados e assentados sintetizavam a sua crítica à escola que conheciam: seja aquela em que tinham estudado, seja aquela que seus filhos tinham freqüentado antes do seu engajamento na luta pela terra. $\mathrm{O}$ adjetivo também embute um componente utópico, como se fosse a escola que sonhavam para os seus filhos. Isso pode representar o desejo de "destruir" o modelo de escola pública, do meio rural 
existente e tentar "construir" uma nova escola que tivesse por princípio, na prática pedagógica e educativa, o MST. Seria a escola que conseguisse criar antídotos contra a inércia, a acomodação, a morosidade, a burocracia, a submissão. Nesse momento, duas questões eram postas para serem discutidas e acabaram sendo o norte para a elaboração da proposta pedagógica: "O que queremos com as escolas de assentamento?" e "Como fazer a escola que queremos?" Essas duas questões sintetizam a preocupação com as diretrizes políticas da luta pelo campo e com a ação cotidiana das escolas já existentes.

Para elaboração da proposta pedagógica, o princípio fundamental é o de que, nas escolas dos assentamentos, toda aprendizagem e todo ensino devem partir da REALIDADE. Essa realidade é tomada no sentido de realidade próxima e/ou distante. Assim ela é definida:

realidade é o meio em que vivemos. É tudo aquilo que fazemos, pensamos, dizemos e sentimos na nossa vida prática. É o nosso trabalho. É a nossa organização. É a natureza que nos cerca. São as pessoas e o que acontece com elas. São os nossos problemas do dia a dia, também os problemas da sociedade que se relaciona com a nossa vida pessoal e coletiva (Caderno de Educação $n^{0} 1$ ).

Esse princípio educativo tem a
REALIDADE como ponto de partida e ponto de chegada, o que implica dizer que tudo o que as crianças estudam deve estar ligado com sua vida prática e com necessidades concretas suas, de seus pais e de sua comunidade; implica também considerar que todos os conhecimentos que as crianças vão produzindo na escola devem servir para que elas entendam melhor o mundo em que vivem, o mundo da sua escola, da sua família, do assentamento, do município, do MST, do País e para que participem da solução dos problemas que esses mundos vão apresentando.

A matriz teórica do referido princípio educativo está em Paulo Freire. Ele diz que a posição normal do homem não é só a de "estar na realidade", mas de "estar com ela". Esse posicionamento teórico exige a opção por uma educação libertadora. Ainda é FREIRE quem afirma:

esta educação, em que educadores e educandos se fazem sujeitos do seu processo, essa educação supera o intelectualismo alienante, supera o autoritarismo do educador "bancário", supera, ainda, a falsa consciência do mundo (1970:86).

Um outro ponto de convergência é que ter a realidade como princípio fundamental exige optar por uma concepção problematizadora de educação, em que educador e educandos são investigadores críticos da realidade. Para o 
autor, "a educação problematizadora, de caráter autenticamente reflexivo, implica num constante ato de desvelamento da realidade" (1970:80).

Assim, o currículo vai ser organizado respeitando esse princípio. Tem como característica partir da realidade próxima da criança e tem a PRÁTICA como centro, o que implica garantir que as crianças tenham várias experiências de trabalho prático e com utilidade real, que tenham oportunidades de aprender a se organizar, a trabalhar em grupo, dividindo tarefas, tomando decisões, resolvendo problemas que a prática vai apresentando.

Nesse sistema, os conteúdos não se estruturam de forma linearmente concatenados, obedecendo a uma suposta diretriz, nem são frutos de uma coerência ou expressão de um grupo que desconhece as condições sociais, políticas e materiais da Escola e do Movimento. O currículo toma uma configuração praxeológica, pois ele é construído num processo aberto por parte dos agentes participantes: professores, alunos, pais, lideranças do MST.

Ele vai, por conseguinte, diferenciar-se ele vai se diferenciar dos currículos tradicionais em três pontos básicos:

1) a sala de aula deixa de ser o centro do processo de ensino e aprendizagem - aprende-se e se ensina a partir da prática, onde quer que ela aconteça;

2) os conteúdos (matemática, por- tuguês, história, geografia, ciências, etc.) passam a ser escolhidos em função de necessidades que a prática vai criando, servindo como instrumento para a construção do conhecimento da realidade e não como fins em si mesmos;

3) a organização do currículo passa pelo coletivo do assentamento, incluindo aí professores que conheçam profundamente a realidade do assentamento, assentados que devem ter conhecimento do que se passa na escola e pelas crianças, que precisam ter a oportunidade de discutir os conhecimentos que vão produzindo na escola.

Se o currículo tem a PRÁTICA como centro, é a categoria TRABALHO que delineia a organização do processo pedagógico. O processo educativo parte de situações concretas de trabalho. Isso implica aprender a se organizar e trabalhar em conjunto e de modo cooperativo, aprender a tomar decisões no coletivo, a dividir tarefas e responsabilidades, a planejar e avaliar o trabalho seu e dos seus companheiros, bem como desenvolver na prática os valores de solidariedade e de disciplina. Quanto mais experiências práticas a criança tiver, mais sólida e significativa será sua aprendizagem e mais crítica ela se torna. $\mathrm{O}$ importante é que essa vivência prática não seja de situações artificiais ou forçadas de trabalho, mas sim que surjam 
pela própria necessidade da escola e da comunidade.

Quando se fala na questão da prática, não se elimina o trabalho sistemático de sala de aula, pois a relação entre prática e teoria, dentro do processo pedagógico, tem o grande desafio de aprender a articular o maior número de saberes diante de situações da realidade.

Assim, acreditar que a produção do conhecimento se dá através da prática exige considerar quão importantes são os momentos de sala de aula, onde o professor vai explicar os conteúdos e os alunos vão estudá-los, fazer exercícios, escrever, perguntar, errar, acertar... Há uma articulação entre o trabalho das crianças e o estudo dos conteúdos na sala de aula. $\mathrm{O}$ momento da sala de aula é o momento da reflexão do conhecimento. Na sala de aula, o conteúdo é trabalhado em várias situações, para poder ser entendido em toda a sua complexidade.

Nesse currículo, onde a categoria TRABALHO aparece como centro, o PLANEJAMENTO é ponto crucial. Se planejar é refletir antes de agir, o planejamento precisa contemplar objetivos a curto, médio e longo prazo.

O PLANEJAMENTO não pode perder de vista os objetivos da escola. Há objetivos que são óbvios, como o desenvolvimento das habilidades de ler, calcular, escrever, mas outros objetivos dependem da realidade específica e vão se alterando e/ou delineando à medida que mudanças vão ocorrendo no conjunto do Assenta- mento e da Sociedade. É importante que não seja o professor sozinho o responsável em definir os objetivos, a comunidade também deve assumir parte desse papel.

A estratégia para estudar a realidade, começando pela mais próxima do Assentamento e indo para a mais distante, se dá através do estabelecimento de TEMAS GERADORES. FREIRE diz que "os temas, em verdade, existem nos homens, em suas relações com o mundo, referidos a fatos concretos" (1970:116). É possível afirmar que existe uma relação entre o fato objetivo, a percepção que os homens têm dele e os temas geradores.

Portanto, os temas geradores são assuntos, questões ou problemas tirados da realidade das crianças e da sua comunidade. Eles permitem direcionar toda a aprendizagem para a construção de um conhecimento concreto e com sentido real, tanto para os alunos como para a comunidade. São esses temas que vão determinar a escolha dos conteúdos, a metodologia de trabalho em sala de aula, a avaliação, entre outros. A organização do trabalho pedagógico através de temas geradores rompe com uma pedagogia centrada nos conteúdos das diversas áreas de conhecimento e passa a ter como norte do trabalho a questão: “para que estudar...”? O conteúdo passa a ser considerado como o conhecimento científico que ajuda a realizar o trabalho e a responder as perguntas sobre a realidade.

Para definir o "para quê" é preci- 
so considerar três pontos básicos:

- Qual a contribuição prática que se tem ao estudar determinado tema?

- Que questões, consideradas como principais, devem ser tratadas nesse momento? (um tema pode ser bastante amplo o que exige um recorte que pode ser feito considerando o tempo, grau de ensino, a idade das crianças, e até para focalizar a questão principal).

- Quais são os objetivos específicos da série em que está trabalhando? Por exemplo, as séries iniciais têm por objetivo a Alfabetização. As crianças vêm para a escola para ler, escrever, contar. $\mathrm{O}$ estudo por temas deve tornar mais fácil essa aprendizagem e jamais deixá-la de lado.

Os temas são escolhidos a partir de uma discussão no coletivo na qual têm voz ativa: professores, alunos e assentados. A escola pode optar em trabalhar grandes temas que serão subdivididos em subtemas menores. Um tema se engata no outro e assim vai acontecendo o conhecimento da realidade e a ligação entre teoria e prática, ou ainda o mesmo tema pode ser trabalhado em séries diferentes, desde que não se perca de vista o objetivo da série.

No planejamento das aulas, o professor deve ter o cuidado de escolher os conteúdos que podem ajudar as crianças a entender melhor os temas que estão sendo estudados ou o trabalho que se está fazendo. O conteúdo assume um caráter instrumental, é meio e não um fim em si mesmo. Essa postura, frente aos conteúdos, não exclui a possibilidade de que a escola tenha uma lista de conteúdos mínimos em cada área e para cada série, mas para servir como norte e não como "camisa de força". O professor busca na lista de conteúdos aqueles que melhor servem para os objetivos do estudo e da prática que os alunos estão realizando.

A diversificação das atividades é fator positivo na construção do conhecimento. Por isso, é fundamental que a criança tenha atividades variadas ao estudar o mesmo conteúdo. Isso facilita a transferência através de uma prática para outras situações.

Um outro ponto a considerar é que assim como os conteúdos não podem representar "uma camisa de força", não se concebe a mesma postura em relação ao tema gerador. Isso quer dizer que o professor não pode ignorar os conhecimentos políticos, sociais e culturais, que acontecem diariamente, porque o seu tema de estudo, naquele momento, não trata disso. Assim, o trabalho prático é atravessado por muitas vozes, temas transversais, provenientes de situações políticas, sociais e ou culturais, que podem ou não ser articuladas com o tema em estudo. Tais temas transversais fazem com que a escola seja ágil, dinâmica e engajada com a realidade.

Essa posição metodológica exige uma prática de avaliação do trabalho que não pode só se voltar para os conteúdos, mas para perceber como e quanto do conhecimento sobre a rea- 
lidade os alunos estão conseguindo se apropriar. Leva também em consideração comportamentos e atitudes demonstrados nos relacionamentos com os companheiros, e ainda, como a escola é local de preparação de militantes. O momento da avaliação não pode descartar a discussão sobre a disponibilidade demonstrada, por cada um, para trabalhar pelo interesse coletivo.

Há dois momentos em que a avaliação é imprescindível:

- durante o trabalho - aquele momento em que se pára a fim de refletir sobre o trabalho em andamento; e

- depois do trabalho desenvolvido - aquele momento em que se faz uma revisão completa, sobretudo do que aconteceu durante o período de tempo, e prepara-se o trabalho seguinte para que seja melhor.

Servem como instrumentos de avaliação: fichas de observação de cada aluno e da turma, feitas pelo professor. Com essas fichas o professor pode acompanhar o desenvolvimento coletivo e pessoal da turma. Um outro instrumento é o diário das crianças, livro de vida individual, onde os alunos registram diariamente o que acontece na classe e com eles, e o que estão sentindo em relação a escola e a tudo o que fazem nela. Esse diário, além de ser um bom exercício de escrita, é também fonte onde o professor deve beber para repensar o seu trabalho docente. As provas escritas não são descartadas. Numa sociedade marcada por provas de seleção, concursos, testes, aprender a fazer prova não é tão negativo.

A questão polêmica que envolve a prova é que a mesma depende do contexto e dos objetivos para os quais se realiza. A prova precisa perder o caráter de ameaça e punição. O seu caráter, nesta proposta, é de estímulo ao crescimento de cada um e do grupo inteiro. Há, ainda, a roda de discussão livre (assembléia), que se constitui num espaço aberto onde todos possam expressar o que estão sentindo, o que estão pensando e o que estão esperando da escola.

$\mathrm{Na}$ maioria das escolas, o poder de avaliar está nas mãos do professor. Ele avalia a todos os alunos e os alunos não podem avaliá-lo. Nesta proposta, todo o processo educativo acontece de modo coletivo. A avaliação não pode ser diferente: é o coletivo da escola que deve fazer a avaliação, cada um com sua responsabilidade e capacidade. Assim:

- cada aluno precisa ter a oportunidade de avaliar a si mesmo, nas várias dimensões: no trabalho, no estudo, no relacionamento;

- os alunos devem avaliar-se entre si e também avaliar o professor;

- o professor precisa se auto-avaliar, bem como e avaliar cada aluno e o conjunto de todos os alunos;

- a comunidade deve avaliar e ser avaliada nas suas relações com a escola.

Em síntese, são pontos fundamentais para o desenvolvimento deste currículo: 
1) A escola deve ser para a criança a principal experiência prática de trabalho cooperativo e de aprendizagem concreta da democracia.

Nesse sentido, a escola pode se organizar como uma espécie de cooperativa onde as crianças, junto com os professores e os assentados, participam de todo o seu funcionamento.

2) A escola deve ser uma grande estimuladora de práticas leitoras.

Todas as experiências de trabalho, toda a organização de aprendizagem prática só têm sentido se forem refletidas e atravessadas pelo estudo e pela teoria. A leitura é uma das grandes fontes de informação e formação, de alargamento de horizontes; assim, a leitura apresenta-se como uma atividade que possibilita a participação do homem na vida em sociedade, em termos de compreensão do presente e do passado, e de possibilidades de transformação futura. E, por ser um instrumento de aquisição e transformação do conhecimento, a leitura constitui-se como um trabalho de combate à alienação, capaz de facilitar ao leitor a realização de sua plenitude. Daí o papel fundamental da escola como a grande estimuladora de práticas de leitura e provedora de textos e livros, não só entre as crianças mas também no conjunto dos assentados.

3) A escola deve trabalhar permanentemente as expressões culturais dos assentados e da luta pela terra como um todo.
A cultura está sendo entendida como a esfera ou campo social que produz significados. A matéria-prima da expressão cultural é a própria vida, que acontece num determinado tipo de sociedade e dentro de relações históricas e sociais. Expressões culturais referem-se à linguagem, a arte, a religião, aos diversos saberes, às crenças, aos valores.

4) A escola deve ser também um espaço de exercício prático dos valores que caracterizam o novo homem, a nova mulher, a nova sociedade.

Democracia, organização, trabalho cooperativo, nova cultura, militância. Tudo isso requer, além do esforço coletivo, uma mudança pessoal, uma disposição de cada um viver segundo uma nova ética de comportamento e de relacionamento entre as pessoas. Isso implica:

- trocar o individualismo pelo espírito de sacrifício, pelo avanço do coletivo;

- trocar o autoritarismo pelo diálogo e pelo respeito às decisões do grupo;

- abandonar o machismo e estabelecer o respeito e a solidariedade entre os sexos.

Esses pontos indicam que no MST o conceito de educação não se confunde com o conceito de escola. Educação é prática social. Essa concepção supõe entender o ato educativo como coisa viva, é o seu acontecer; não se dicotomiza trabalho e vida, mas o trabalho é tomado 
como vida e vice-versa. Portanto, essa prática não se dá apenas no espaço da escola.

A proposta pedagógica a que nos referimos traz em seu bojo princípios tão atuais e tão antigos. Sustenta em termos metodológicos exigências que há muito se faz à escola: superar o ensino livresco e fragmentado e voltar para as questões da realidade vivida pelos alunos e seus grupos sociais; estabelecer processos de construção coletiva e pessoal do conhecimento; tornar as aprendizagens mais significativas e efetivas. Qualquer "manual" (Manual?! Quer coisa mais démodé?!) de psicologia da aprendizagem e de didática trazem esses princípios.

O MST tem muita clareza quando marginaliza a escola real, falida, que chega às camadas populares, $\mathrm{e}$ busca uma experiência alternativa sem cair em proposições imaginárias, mas mergulhada no cotidiano das relações sociais. Só assim é possível a construção da Escola Necessária para se defender como classe e para a transformação coletiva de sua condição de classe. Este é, com certeza, um grande projeto político social. Mas, uma questão fica para reflexão: essa proposta tem como base "prescrições genéricas" para serem reelaboradas e efetivadas por professores e professoras que atuam nas escolas dos assentados. Quem são esses professores e professoras? Qual a sua formação?

Essa é sem dúvida a escola que todos nós queremos, mas para que essa proposta seja efetivada não podemos desconsiderar as condições de trabalho, culturais, sociais e de formação pedagógica daqueles que têm a responsabilidade de consolidar esse grande projeto social, o qual exige um professor ou professora que seja consciente, crítico, atuante, e tecnicamente competente.

\section{REFERÊNCIAS \\ BIBLIOGRÁFICAS}

1 CALDART, Roseli.(1995). Os Movimentos Sociais e a Construção da Escola (do sonho) possível. Porto Alegre. (texto mimeografado).

2 _. Educação em Movimento-Formação de Educadores e educadoras no MST (1997). Petrópolis: Vozes.

3 FREIRE, Paulo. (1970). Pedagogia do Oprimido. $7^{\text {a }}$ ed. Rio de Janeiro: Paz e Terra.

4 FREIRE, Paulo, GUIMARÃES, Sérgio (1982). Sobre Educação- Diálogos. $4^{\mathrm{a}}$ ed. Rio de Janeiro: Paz e Terra.

5 CADERNOS DE EDUCAÇÃO. Como fazer a escola que queremos. Porto Alegre,MST, n. $1,1992$.

6 CADERNOS DE EDUCAÇÃO. Princípios da Educação no MST. Porto Alegre, n.8, 1997. 